\title{
Massive pulmonary embolism in late pregnancy
}

David K.Woodward MB CHB MRCP (UK) FRCA, Richard J.S. Birks MBChB FRCA, Kath A. Granger MB BS MRCOG

Purpose: To describe the management problems presented by a case of acute massive pulmonary embolism in a labouring woman.

Clinical Features: A case of massive pulmonary embolism is described in a woman who presented in early labour at thirty-eight weeks gestation. Immediate management involved the administration of oxygen and intravenous heparin, and transfer to the regional cardiothoracic centre. Pulmonary angiography confirmed the diagnosis of massive pulmonary embolism, but attempts at percutaneous catheter disruption of the clot were of only temporary benefit. The patient subsequently underwent Caesarean section under general anaesthesia, followed minutes later (because of an abrupt deterioration in her condition) by surgical pulmonary embolectomy. The outcome was successful for both mother and child.

Conclusion: In cases of acute massive pulmonary embolism presenting in late pregnancy and in labour, the risks and benefits of surgical embolectomy, pharmacological thrombolysis, or attempts at mechanical clot disruption have to be weighed on an individual basis. Management at the referral centre was facilitated by having cardiothoracic and obstetric facilities on the same site.

Objectif : Décrire les problèmes de traitement d'une embolie pulmonaire massive d'apparition brutale chez une parturiente en travail.

Aspects cliniques : Un cas d'embolie pulmonaire massive est décrit chez une femme qui s'est présentée à trente-huit semaines de grossesse, en travail obstétrical prématuré. Le traitement immédiat a consisté à administrer de l'oxygène et de l'héparine intraveineuse et de diriger la patiente vers le centre cardiothoracique régional. L'angiographie pulmonaire a confirmé le diagnostic d'embolie pulmonaire massive, mais des essais pour rompre le caillot à l'aide de cathéter percutané n'ont eu que des effets temporaires. La patiente a subi ensuite une césarienne sous anesthésie générale, suivie quelques minutes plus tard (à cause de la détérioration soudaine de son état) d'une embolectomie pulmonaire réussie avec succès pour la mère et l'enfant.

Conclusion : Lors d'une embolie pulmonaire massive d'apparition brutale, qui se présente vers la fin de la grossesse et pendant le travail, les risques et les avantages de l'embolectomie, la thrombolyse pharmacologique ou les essais de rupture mécanique du caillot doivent être évalués sur une base individuelle. Le traitement au centre spécialisé a été facilité ici par le fait d'avoir les senvices cardiothoraciques et obstétricaux au même site.

From the Departments of Anaesthesia, Northern General Hospital and Royal Hallamshire Hospital, and the Department of Obstetrics and Gynaecology, Northern General Hospital, Sheffield. Address correspondence to: Dr. R.J.S. Birks, Department of Anaesthetics, Royal Hallamshire Hospital, Sheffield S10 2JF United Kingdom.

Phone: 44-114-2712494; Fax: 44-114-2798314

Accepted for publication June 17, 1998. 
$\mathrm{P}$

REGNANCY is a recognised risk factor for venous thrombo-embolic disease (VTE), although the occurrence of life-threatening pulmonary embolism is rare. The term venous thrombo-embolism (VTE) embraces both deep vein thrombosis (DVT) and pulmonary embolism (PE), and its occurrence in pregnancy has recently been reviewed. ${ }^{1,2}$ Venous thrombo-embolism has an estimated incidence of 1:1,000-2,000 pregnancies; ${ }^{3}$ pregnancy increases the risk of VTE five fold (compared with non-pregnant women in the same age group) ${ }^{4}$ with the greatest risk being in the puerperium. ${ }^{5}$ Venous thrombo-embolism is the leading cause of direct maternal death during pregnancy in the UK, ${ }^{6}$ accounting for 35 deaths in the 1991-1993 triennium; 30 of these were due to pulmonary embolism. There has been no change in incidence of maternal deaths due to VTE over the last three triennia, despite the now routine use of subcutaneous heparin in those deemed to be at particular risk. We report a case of massive pulmonary embolism occurring in a labouring woman at thirty-eight weeks gestation, and discuss the subsequent management.

\section{Case Report}

A 25 yr old Caucasian woman in the 38th week of her second pregnancy presented to the ante-natal ward of a local district general hospital with a two hour history of an abrupt onset of severe dyspnoea, chest tightness, and dizziness. Examination demonstrated central cyanosis and tachycardia, although she was normotensive (blood pressure (BP) $110 / 70 \mathrm{mmHg}$ ). A clinical diagnosis of pulmonary embolism was made, and, following initiation of treatment with oxygen and intravenous heparin, she was transferred immediately to the cardiothoracic unit at this hospital.

On arrival on the cardiac intensive care unit (four hours after initial presentation), the patient was found to be conscious, tachypnoeic and cyanosed, with an $\mathrm{SpO}_{2}$ of $89 \%$ breathing oxygen by face mask (nominal $\mathrm{F}_{1} \mathrm{O}_{2}$ of 0.9 ). She was tachycardic (pulse rate $140 \mathrm{bpm}$ ) but remained normotensive (BP $125 / 75 \mathrm{mmHg}$ ). Blood gas analysis demonstrated a $\mathrm{pH}$ of $7.44, \mathrm{PaCO}_{2}$ of $3.5 \mathrm{kPa}, \mathrm{PaO}_{2}$ of $7.7 \mathrm{kPa}$ and base deficit of 5.3 $\mathrm{mmol} \cdot \mathrm{l}^{-1}$. An ECG demonstrated sinus tachycardia with partial right bundle branch block, and right ventricular strain. Cardiotocography indicated fetal well-being (with a baseline rate of $150 \mathrm{bpm}$ and good variability). The presence of regular 'tightenings' and vaginal examination confirmed that the patient was in early labour.

The immediate management of the patient was discussed with obstetrics, cardiothoracic surgery, cardiology, anaesthetics and radiology. In view of the evidence of early labour, it was considered that to pro- vide the best chance of survival for both mother and child, delivery by urgent Caesarean section was indicated. The need for surgical pulmonary embolectomy was a distinct possibility, and pulmonary angiography was required to confirm the diagnosis; attempts at mechanical clot disruption during this investigation also held the possibility of improving the patient's haemodynamic status. ${ }^{7}$ As the patient was at term and in early labour, and an active surgical approach to management had been selected, pharmacological thrombolysis to supplement percutaneous mechanical clot fragmentation was considered too dangerous because of the attendant risks of bleeding.

The patient subsequently underwent pulmonary angiography (two hours after arrival at our hospital), which confirmed bilateral large proximal pulmonary emboli, with preserved perfusion only of the left upper lobe. Attempts at mechanical disruption of the proximal thrombus using a pigtail catheter were met with some improvement in her symptoms and arterial oxygen saturation, and radiologically improved perfusion to the right lung. An infra-renal caval filter was inserted.

However, the initial improvement in the patient's condition was not maintained, and re-examination within the hour confirmed progression of labour; the fetal heart rate remained satisfactory. It was, therefore, decided to proceed to delivery of the baby by Caesarean section under general anaesthesia, with full preparation being made to proceed to emergency surgical pulmonary embolectomy if indicated.

She received premedication with sodium citrate and $50 \mathrm{mg}$ ranitidine $i p$, and a radial arterial cannula for blood pressure monitoring was secured. She was transferred to theatre three hours and ten minutes after admission. Following pre-oxygenation, general anaesthesia was induced with $500 \mu \mathrm{g}$ alfentanil and $20 \mathrm{mg}$ etomidate, and $100 \mathrm{mg}$ succinylcholine was given to facilitate tracheal intubation after cricoid pressure was applied and tracheal intubation was easily performed. Maintenance of anaesthesia was by means of ventilation with oxygen, isoflurane $1 \%$, with vecuronium for relaxation. Alfentanil $500 \mu \mathrm{g}$, followed by $300 \mu \mathrm{g}$ fentanyl, were given after delivery of the baby.

A pre-induction BP of $140 / 70 \mathrm{mmHg}$ decreased to $95 / 70 \mathrm{mmHg}$ post-induction, and increased to $140 / 95 \mathrm{mmHg}$ during delivery. A live but asphyxiated $3.8 \mathrm{~kg}$ male infant was delivered within ten minutes of induction of anaesthesia (and just under four hours after the patient had been admitted to this hospital). Apgar scores: 1 at $1 \mathrm{~min} ; 2$ at $5 \mathrm{~min} ; 6$ at $10 \mathrm{~min} ; 8$ at $15 \mathrm{~min}$ ). Following administration of $10 \mathrm{IU}$ syntocinon and fentanyl post-delivery, the BP decreased to $80 / 60 \mathrm{mmHg}$. A sinus tachycardia of $140-160 \mathrm{bpm}$ persisted throughout this period. However, approxi- 
mately ten minutes after delivery, and while the uterus was being closed, the patient's blood pressure decreased suddenly to $50 / 30 \mathrm{mmHg}$. On suspicion of a further massive $\mathrm{PE}$, median sternotomy was performed, and normothermic, non-cardioplegic cavoaortic cardiopulmonary bypass was instituted following full heparinisation. A $20 \mathrm{~cm}$ length of embolic thrombus was extracted from the main pulmonary artery bifurcation. An innominate vein central line was inserted by the surgeon following embolectomy, (as attempts at internal jugular line insertion following delivery had been interrupted by the need to institute CPB); the CVP after separation from CPB was 10 $\mathrm{cmH}_{2} \mathrm{O}$.

An adrenaline infusion $\left(0.1-0.2 \mu \mathrm{g} \cdot \mathrm{kg}^{-1} \cdot \mathrm{min}^{-1}\right)$ was required to support separation from cardiopulmonary bypass, and this was continued throughout a ten hours of post-operative ventilation. The heparin was reversed with $200 \mathrm{mg}$ protamine when CPB was discontinued, and a syntocinon infusion of 20 IU over five hours was commenced in theatre.

Pre-operatively, $\mathrm{Hb}$ was $98 \mathrm{~g} \cdot \mathrm{l}^{-1}$ and platelet count $87 \times 10^{9} \mathrm{I}^{-1}$. Following delivery, per-operative $\mathrm{Hb}$ was $82 \mathrm{~g} \cdot \mathrm{l}^{-1}$, and decreased to $55 \mathrm{~g} \cdot \mathrm{l}^{-1}$ during cardiopulmonary bypass (co-oximetry values). The patient received three units of blood (packed cells or SAG-M) in theatre and, subsequently, a further three units overnight in the CICU. In view of the pre-operative thrombocytopenia, period of CPB, and six unit blood transfusion, she was also given five units each of platelets and FFP in CICU. However, there was no evidence of excessive obstetric haemorrhage either in theatre or post-operatively. The patient's arterial blood gas values are recorded in the table.(Table)
Following extubation, she continued an uneventful post-operative course, with good oxygenation on an $\mathrm{FIO}_{2}$ of 0.4 . She was discharged to the post-natal ward 24 hr later. Subcutaneous heparin (5,000 IU bd) was commenced on the first post-operative day, for two days, and warfarin on the second post-operative day. She was discharged home seven days after admission, and she and the baby were progressing well. The caval filter was removed on the tenth post-operative day, as an outpatient procedure.

\section{Discussion}

It is estimated that two thirds of those dying from the haemodynamic consequences of acute massive PE will do so within two hours. However, deaths continue to occur in the next $24-48 \mathrm{hr}$, due to deposition of further thrombus in the pulmonary arteries. ${ }^{8}$ The initial management of VTE in both pregnant and non-pregnant patients includes the administration of heparin by intravenous infusion. ${ }^{1}$ Its effect in reducing mortality is probably by discouraging further thrombus deposition rather than by ameliorating the acute haemodynamic consequences of pulmonary artery obstruction, as it has no significant thrombolytic effect. ${ }^{8}$

There are a number of recent case reports of massive PE in pregnancy, ${ }^{9-13}$ almost all occurring before $30 \mathrm{wk}$ gestation, in which management has involved the use of thrombolytic agents (streptokinase, urokinase, recombinant tissue plasminogen activator, (rt-PA), following diagnosis by means of pulmonary angiography or ventilation-perfusion radionuclide scanning. Despite concerns that thrombolysis may lead to placental abruption, this complication did not occur. In addition, cases treated with thrombolysis that were not in labour either had

TABLE Arterial blood gas values in relation to events

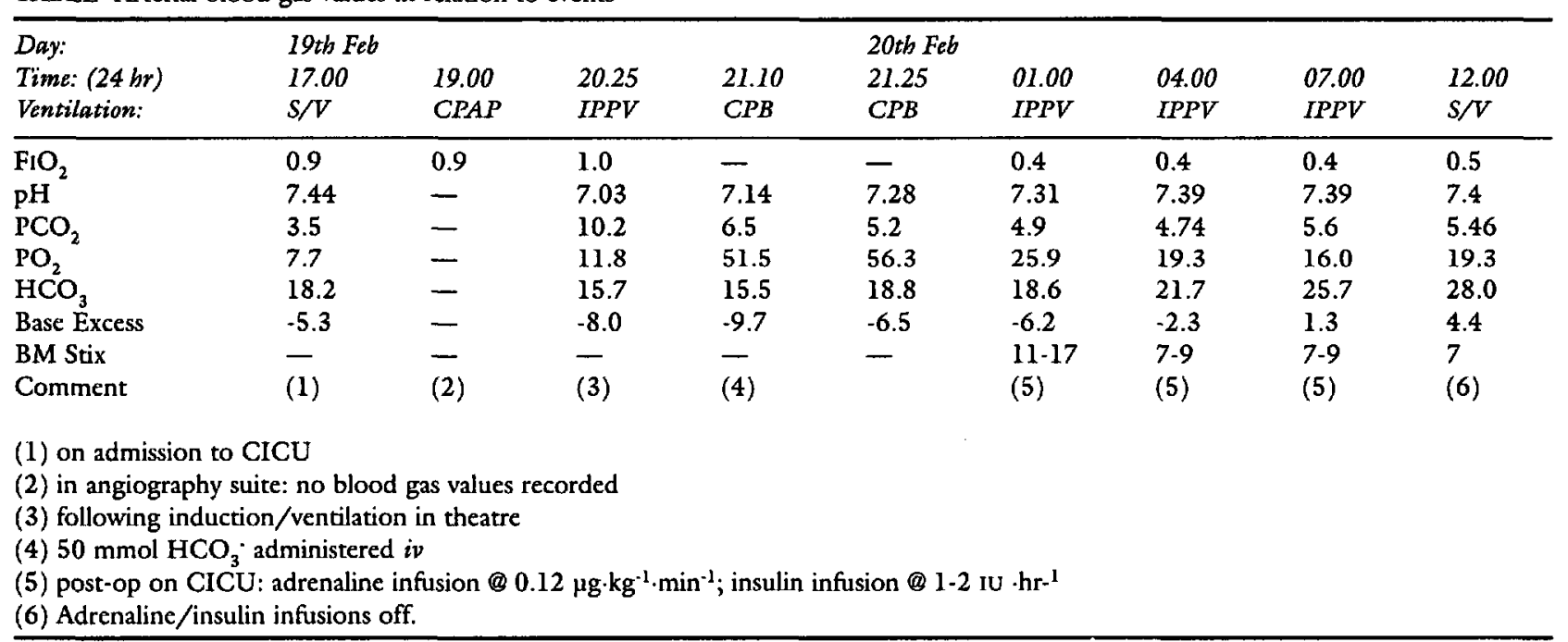

(CPAP = continuous positive airway pressure; IPPV $=$ intermittent positive pressure ventilation). 
no, ${ }^{10,11,13}$ or limited ${ }^{9}$ obstetric bleeding, all proceeding to successful outcomes of pregnancy.

Considerable problems with obstetric haemorrhage have occurred, however, in a case reported in $1972^{14}$ in which streptokinase was infused throughout labour and delivery, only being discontinued in the third stage due to persisting blood loss which was finally controlled with aminocaproic acid. In a more recent report, ${ }^{12}$ streptokinase was commenced for massive $\mathrm{PE}$ at 28 wk gestation, but was stopped after $10 \mathrm{hrs}$ for the duration of a pre-term labour and delivery. It was recommenced eight hours later, but discontinued after a total of $29 \mathrm{hr}$ and substituted with heparin. The total post-partum blood loss reached $8900 \mathrm{ml}$ by the 5 th day.

The technique of percutaneous transvenous fragmentation of pulmonary emboli may be performed using catheters specifically designed for the purpose, or with conventional cardiac catheters. A case report of acute massive P.E. involving three non-obstetric cases ${ }^{7}$ demonstrated this to be a rapid and relatively non-invasive method of improving cardiac output in very sick patients. Two cases subsequently also received an infusion of streptokinase via a pulmonary artery catheter, although the dramatic haemodynamic improvement occurred prior to this, and was maintained in the third case in whom thrombolysis was contra-indicated. The authors questioned whether the streptokinase conferred any additional benefit over and above fragmentation. A combination of streptokinase and percutaneous catheter fragmentation has also been used successfully in pregnancy at 25 wk gestation. ${ }^{9}$

A case report in 1985 discussed a woman presenting at 35 wk gestation with a massive PE, in active labour. ${ }^{15}$ Despite cardiorespiratory compromise, labour was allowed to proceed and resulted, eight hours later, in the spontaneous vaginal delivery of a $2.3 \mathrm{~kg}$ live infant. Caesarean section was rejected as it was felt that the maternal risk was too great; any surgical intervention should be for 'maternal indications' only (such as embolectomy for worsening status). Thrombolytic therapy was also rejected as carrying too high a risk. However, following delivery, elective ventilation was instituted to maximise oxygen delivery and avoid maternal exhaustion. The patient underwent a V/Q scan, which was positive. Before angiography and caval filter insertion could be performed, she decompensated and required surgical embolectomy. Both mother and baby subsequently fared well.

A case bearing some similarity to ours was reported in $1989,{ }^{16}$ in which a woman presented with cardiorespiratory compromise due to acute $\mathrm{PE}$, at 32 wk gestation. She was not in labour. Heparin was commenced four hours after admission, but there is no record of whether thrombolytic agents were considered. Five hours after admission, emergency Caesarean section was performed because of fetal bradycardia. The technique used involved awake intubation, prior to induction with ketamine. Following delivery of an asphyxiated $1.86 \mathrm{~kg}$ infant, pulmonary artery catheter insertion was attempted, but abandoned after a brief episode of ventricular tachycardia. Blood pressure subsequently decreased to $40 / 20 \mathrm{mmHg}$, following which pulmonary embolectomy on cardiopulmonary bypass was performed. Separation from CPB required $5 \mu \mathrm{g} \cdot \mathrm{kg}^{-1} \cdot \mathrm{min}^{-1}$ dopamine, $.3 \mu \mathrm{g} \cdot \mathrm{kg}^{-1} \cdot \mathrm{min}^{-1}$ isoproterenol, and 0.8 $\mu \mathrm{g} \cdot \mathrm{kg}^{-1} \cdot \mathrm{min}^{-1}$ adrenaline. Heparin was fully reversed with protamine, and she was transfused a total of eight units of blood, and 20 units of platelets (her platelet count on admission was $49 \times 10^{9}$ per litre). Despite $5 \mathrm{IU}$ oxytocin and 'adequate uterine tone' following delivery, she was discovered to have bled $2,000 \mathrm{ml}$ per vaginum when the drapes were removed. Both mother and child had an uneventful recovery.

Our case presented at term, in early labour. Having confirmed the diagnosis angiographically, percutaneous catheter fragmentation did not lead to sustained haemodynamic improvement. The condition of the patient at this stage was considered too precarious to expect her to proceed successfully through labour, as haemodynamic collapse during a trial of labour would have demanded simultaneous resuscitation and immediate surgical intervention, with slim prospects for the survival of either mother or child. Our concerns about the risk of commencing thrombolytic therapy in active labour are borne out by the experience of others. ${ }^{12,14}$ Thus, our management plan was to perform emergency Caesarean section (for both maternal and fetal benefit), fully prepared to proceed to surgical embolectomy if indicated. The sudden haemodynamic collapse within minutes of delivery suggests that either manipulation within the pelvis precipitated a further embolic event, or that obstruction by the pre-existing saddle embolus had worsened. The presence of a caval filter makes the latter more likely. The baby at delivery was severely asphyxiated: as delivery occurred before cardiopulmonary bypass, the asphyxia was more likely to reflect the period of hypoxia, acidosis and placental hypoperfusion prior to delivery than the decision to intervene surgically. Despite full heparinisation for the period of cardiopulmonary bypass immediately following delivery, severe uterine haemorrhage did not occur.

In conclusion, recent case reports support the use of thrombolysis and percutaneous catheter fragmentation in cases of massive P.E. occurring in pregnant women not in labour; furthermore, this should be performed early, and arguably does not require cardiac catheterisation facilities.' Use of thrombolytic agents during labour and delivery can be expected to be associated 
with peri-partum haemorrhage, and the risks and benefits of conservative management $v s$ thrombolysis or surgical embolectomy must be made on an individual basis in these patients. However, some maintain that thrombolysis should be strongly contraindicated in the peripartum period until evidence from controlled trials is available. ${ }^{15}$ It may be that increasing experience with 'clot specific' thrombolytic agents (e.g. rt-PA) in pregnancy will further reduce the indications for surgical pulmonary embolectomy. ${ }^{11}$ Finally, after surviving a 40 min inter-hospital transfer, the management of the patient at this unit was greatly facilitated by having both cardiothoracic and obstetric facilities on the same site.

\section{References}

1 Toglia $M R$, Weg JG. Venous thromboembolism during pregnancy. N Engl J Med 1996; 335: 108-14.

2 Brown HL, Hiett AK. Deep venous thrombosis and pulmonary embolism. Clin Obstet Gynecol 1996; 39: 87-100.

3 de Swiet M, Fidler J, Howell R, Letsky E. Thromboembolism in pregnancy. In: Jewell D (Ed.). Advanced Medicine, Vol. 17. Tunbridge Wells: Pitman Medical, 309-17.

4 Prevention of venous thrombosis and pulmonary embolism. National Institutes of Health Consensus Development Conference. JAMA 1986; 256: 744.

5 Ascari E, Siragusa S, Piovella $F$. The epidemiology of deep vein thrombosis and pulmonary embolism. Haematologica 1995: 80 (Suppl2): 36-41

6 HMSO Triennial report into maternal mortality $1991-1993$.

7 Brady AJ, Crake T, Oakley CM. Percutaneous catheter fragmentation and distal dispersion of proximal pulmonary embolus. Lancet 1991; 338: 1186-9.

8 Gray HH, Miller GAH, Paneth M. Pulmonary embolectomy: its place in the management of pulmonary embolism. Lancet 1988; 1: 1441-5.

9 Mazeika PK, Oakley CM. Massive pulmonary embolism in pregnancy treated with streptokinase and percutaneous catheter fragmentation. Eur Heart J 1994; 15: 1281-3.

10 Declos GL, Davila F. Thrombolytic therapy for pulmonary embolism in pregnancy: a case report. Am J Obstet Gynecol 1986; 155: 375-6.

11 Floßdorf Th, Breulmann $M$, Hopf $H-B$. Successful treatment of massive pulmonary embolism with recombinant tissue type plasminogen activator (rt-PA) in a pregnant woman with intact gravidity and preterm labour. Intensive Care Med 1990; 16: 454-6.

12 Fagher B, Ablgren M, Astedt B. Acute massive pulmonary embolism treated with streptokinase during labor and the early puerperium. Acta Obstet Gynecol Scand 1990; 69: 659-61.
13 Kramer WB, Belfort $M$, Saade G, Surani S, Moise KJJr. Successful urokinase treatment of massive pulmonary embolism in pregnancy. Obstet Gynecol 1995; 86: 660-2.

14 Hall RJC, Young C, Sutton GC, Campbell S. Treatment of acute massive pulmonary embolism by streptokinase during labour and delivery. BMJ 1972; 4: 647-9.

15 Richards SR, Barrows $H$, O'Shaughnessy $R$. Intrapartum pulmonary embolus. A case report. J Reprod Med 1985; 30: 64-6.

16 Splinter WM, Dwane PD, Wigle RD, McGrath MJ. Anaesthetic management of emergency Caesarian section followed by pulmonary embolectomy. Can J Anaesth 1989; 36: 689-92. 